\title{
Assimilation of Satellite Observations of the Chlorophyll-a Concentration and the Calculated Data on the Marine Environment Dynamics in the Adaptive Model of the Ecosystem of the Black Sea Northwestern Shelf
}

\author{
I. E. Timchenko, I. P. Naumenko, E. M. Igumnova* \\ Marine Hydrophysical Institute, Russian Academy of Sciences, Sevastopol, Russian Federation \\ e-mail: lazarchuk.syst.analysis@mhi-ras.ru
}

\begin{abstract}
The model of the sea upper layer ecosystem based on the equations of the adaptive balance of causes method is proposed. The scheme of the cause-effect relations from the paper by Fasham, Ducklow and McKelvie constituting the nitrogen cycle reactions in the sea upper layer is used in the model. Parameterization of biochemical reactions of the substance interaction is substituted in this model for the normalized ratios of the substances' average concentrations resulted from analyzing the observations of the biochemical fields of the Black Sea northwestern shelf. The satellite-derived chlorophyll$a$ concentrations as well as the data on advection and diffusion obtained from calculations of intraannual variability of the current velocity field in the sea upper sea layer using the hydrodynamic model, are used as the external influencing factors. Being regarded as the external influencing factors, the information was used for calculating the deviations of the biochemical fields' concentrations from their average values assumed to be a stationary state of the ecosystem. The observations were assimilated through including the sources' additional functions (representing the assimilated data) to the right parts of the adaptive ecosystem model equations. The regional maps of the biochemical fields permitting to analyze their spatial-temporal variability in 2015 were constructed. The drawn conclusion confirms utility of the proposed approach used for mapping the biochemical fields of the sea upper layer.
\end{abstract}

Keywords: adaptive balance of causes method, preservation of material balances, normalized influence coefficients, adaptive model of the sea upper layer ecosystem, maps of biochemical fields.

Acknowledgements: the adaptive model of the marine ecosystem is developed at financial support of the Russian Fund of Fundamental Investigations and the Sevastopol Administration within the framework of the project No. 18-47-920001 "Study of the principles for constructing adaptive models of the ecological-economic systems and digital informational technologies for managing the scenarios of sustainable development of natural and economical complexes in the Seavastopol region”. The computing experiments with the model are performed within the framework of the state task on the theme No. 0827-2018-0004 "Complex interdisciplinary investigations of the oceanologic processes which condition functioning and evolution of the coastal ecosystems of the Black and Azov seas".

For citation: Timchenko, I.E., Naumenko, I.P. and Igumnova, E.M., 2018. Assimilation of Satellite Observations of the Chlorophyll- $a$ Concentration and the Calculated Data on the Marine Environment Dynamics in the Adaptive Model of the Ecosystem of the Black Sea Northwestern Shelf. Physical Oceanography, [e-journal] 25(6), pp. 509-520. doi:10.22449/1573-160X-2018-6-509-520

DOI: $10.22449 / 1573-160 X-2018-6-509-520$

(C) 2018, I. E. Timchenko, I. P. Naumenko, E. M. Igumnova

(C) 2018, Physical Oceanography

\section{Introduction}

Biochemical reactions of substance transformation in the sea upper layer are affected by solar radiation, oxygen and carbon dioxide fluxes through the sea surface, horizontal and vertical transport and mixing of water masses, as well as many other factors. The problem of modeling the variability of the upper layer biochemical fields, which dictates the need for assimilation of the observation data of subPHYSICAL OCEANOGRAPHY VOL. 25 ISS. 6 (2018) 
stance concentration and marine environment dynamics into the ecosystem models, is due to abovementioned factors. The methods of satellite and contact observations assimilation were developed in many studies on the models of ocean and atmosphere dynamics [1-7]. In a number of studies the methods for assimilating satellite observations of chlorophyll concentration, temperature and sea-level elevations, as well as remote observations of floating buoys in the Black Sea circulation models, were developed [8-10]. Due to this, the works in which the models of marine ecosystems are based on hydrophysical equations of substance transport and diffusion, supplemented by the functions of sources and sinks, taking into account the biochemical reactions of substance transformation in the marine environment, appeared.

This allows you to construct the models of marine ecosystems (based on simpler balance models of biochemical processes) subjected to external effects of advection and diffusion on the concentration of modeling substances in ecosystems. An example of this approach is the classic model of the nitrogen cycle in the upper sea layer by Fasham, Ducklow and McKelvie [11]. In this model, the dynamics of the upper mixed layer lower boundary, calculated according to a separate hydrophysical model, controls the mass balances of biochemical reactions by including additional dynamic sources into the system of ordinary differential equations of the ecosystem model.

The effort for simplifying the problem of modeling of the sea upper layer biochemical fields by maximizing the use of observational data, led to the creation of an adaptive modeling approach based on the hypotheses about the existence of an equilibrium state of the ecosystem with the environment and deviations from this state under effect of observable external impacts. These hypotheses allowed us to develop the adaptive balance of causes method ( $A B C$-method) used in this work $[12,13]$, in which ordinary differential equations of special (logistic) type are applied. The method is based on the assumption that the ecosystem seeks the state of dynamic equilibrium, in which the intrasystem processes are adapted to each other and to external effects in such a way, that material balances of substance transformations in the marine environment are preserved. The principle of adaptation leads to the occurrence of relatively simple equations of adaptive models which in its turn allows us to simplify the process of observational data assimilation in the model.

This approach was applied in a number of works by I. E. Timchenko, I. P. Naumenko and E. M. Igumnova, devoted to the assimilation of satellite observations in adaptive models of the upper layer ecosystems for the Black Sea waters. Particularly, in [14] the assimilation of observational data in the adaptive version of the abovementioned model of the nitrate cycle [11], in which the external effect of water mass transfer and diffusion on the concentrations of substances was simulated, was considered. In contrast to the simulation experiments [14], this study aimed to assimilate into the models real satellite data on chlorophyll $a$ concentration, obtained during 2015 in the northwestern part of the Black Sea, and to adapt the model estimates of the upper layer biochemical fields to the calculated archive data on the transfer and diffusion of substances in the mentioned period. 


\section{Adaptive model of the sea upper layer ecosystem}

The basis of the adaptive ecosystem model is the idea of maximal use of observation data of the substance transformation reactions in the marine environment in order to replace the complex parameterization of these reactions with the coefficients of effects estimated by the observations. The $A B C$-method assumes that cause-effect relationships between the modeled processes are known. This makes it possible to construct a scheme of mutual effects - a conceptual model of the ecosystem. It is introduced the assumption about the existence of the ecosystem average equilibrium state, in which the substance concentration change rates are balanced in such a way that, in the absence of external effects, they remain constant.

To explain the essence of this method, we consider a set of ecosystem model variables $\left\{u_{i}\right\}$ which denote the concentrations of substances during their transformations in the marine environment, and determine the average values of the processes $\left\{C_{i}\right\}$ characterizing the stationary condition of the ecosystem. Mutual effects of $n$ processes will be evaluated by the effect coefficients $a_{i j}$, which interconnect the variables $u_{i}$ and $u_{j}$ by the relations

$$
u_{i}=\sum_{j=1, j \neq i}^{n} a_{i j} u_{j} .
$$

These relations can be considered as reactions of ecosystem resource transformation $u_{j}$ into products $u_{i}$. Then the effect coefficients take into account what amount of this type of resource is consumed by the product during this reaction. It is natural to assume that the effect coefficients $a_{i j}$ are preserved when averaging the expressions (1), as well as when taking into account in them the external effects on the ecosystem, which we denote as $A_{i}$. External effects lead to deviations in the substance concentrations from their average statistical values $C_{i}$. The natural requirement is the preservation of the material balances of reactions, taking into account the external effects:

$$
u_{i}-C_{i}=\sum_{j=1, j \neq i}^{n} a_{i j}\left(u_{j}-C_{j}\right)+A_{i} .
$$

The introduced assumptions are used in the adaptive balance of causes method $[12,13]$ to set up standard equations that automatically save the balances (2) of the substance transformation in the ecosystem. These equations have the following form:

$$
\frac{d u_{i}}{d t}=2 r_{i} u_{i}\left\{C_{i}-\left[u_{i}-\sum_{j=1, j \neq i}^{n} a_{i j}\left(u_{j}-C_{j}\right)-A_{i}\right]\right\},
$$

where $r_{i}$ are dimensional parameters that have the meaning of specific rates of variation $u_{i}$. Equations (3) relate the ecosystem variables to negative second-order feedbacks with the variation rates of variables, which ensures quick adaptation of variables to each other and to external effects in order to save the balances (2) [13]. 
For estimating the effect coefficients $a_{i j}$ from observational data, probabilistic and expert methods are proposed [13]. In this study we use approximate estimates based on the known average values of the modeled processes $C_{i}$. First of all, we reduce the resource functions $u_{j}$ included in the balance relations (2) to the ecosystem product variability intervals $\left(0 \leq u_{i} \leq 2 C_{i}\right)$. For this, we express the variables of the ecosystem model in the balance relations (2) in the units of average values of variables. Then we obtain

$$
u_{i}=C_{i}+\sum_{j=1, j \neq i}^{n} a_{i j}^{\prime} \frac{C_{i}}{C_{j}}\left(u_{j}-C_{j}\right)+A_{i}^{\prime} .
$$

The effect of resources $u_{j}$ in the relations (4) is proportional to the values of deviations $\left(u_{j}-C_{j}\right)$, and the degree of these effects is determined by the ratio values of average values $C_{i} / C_{j}$. Therefore, we can assume that the dimensionless factors $a_{i j}^{\prime}$ equally transmit the effects of functions $u_{j}$ on functions $u_{i}$. This allows us to choose them equal, based on considerations of stability of solutions of the $A B C$-method system of equations (3).

From the analysis of the $A B C$-method properties [13] it is know that the stability of the system of equations (3) solutions will be guaranteed if the sums of negative and positive effects in the method equations do not exceed $0.5 C_{i}$. Let, for example, in the equations of the system (3) there are $m$ of positive and $n-m$ of negative effects. Then at the introduced assumptions the system of equations (3) takes the following form:

$$
\begin{gathered}
\frac{d u_{i}}{d t}=2 r_{i} u_{i}\left\{C_{i}-\left[u_{i}-\frac{C_{i}}{2 m} \sum_{\substack{k=1, k \neq i \\
(n>m)}}^{m} C_{k}^{-1}\left(u_{k}-C_{k}\right)+\frac{C_{i}}{2(n-m)} \sum_{l=1, l \neq i}^{n-m} C_{l}^{-1}\left(u_{l}-C_{l}\right)-A_{i}^{\prime}\right]\right\}, \\
(n>m), 2, \ldots, n) .
\end{gathered}
$$

In order for the solutions of equations to satisfy the given intervals of variable variations $\left(0 \leq u_{i} \leq 2 C_{i}\right)$, the system of equations of the model (5) is supplemented with logical management agents

$$
u_{i}=\operatorname{IF}\left[u_{i}<0 ; 0 ; \operatorname{IF}\left(u_{i}>2 C_{i} ; 2 C_{i} ; u_{i}\right)\right] .
$$

We apply the obtained equations to the scheme of cause-effect relations between the processes of nitrogen cycle based on the ecosystem model by Fasham, Ducklow and McKelvie [11]. Conceptual model of the ecosystem is depicted in Fig. 1.

Using the notations of variables and cause-effect relations between them given in Fig. 1, we set a system of equations of the adaptive model of the sea upper layer ecosystem. For the shortening, we will denote the deviations of variables from their average values as $u_{i}^{\prime}=u_{i}-C_{i}$.

Equation of phytoplankton concentration:

$$
\begin{aligned}
& \frac{d P}{d t}=2 r_{P} P\left\{C_{P}-\left[P-C_{P}\left(4 C_{N_{a}}\right)^{-1} N_{a}^{\prime}-C_{P}\left(4 C_{N_{n}}\right)^{-1} N_{n}^{\prime}+C_{P}\left(2 C_{Z}\right)^{-1} Z-F\left(C H^{\prime}\right)-\right.\right. \\
& \left.\left.-D Y N\left(P^{\prime}\right)\right]\right\} .
\end{aligned}
$$




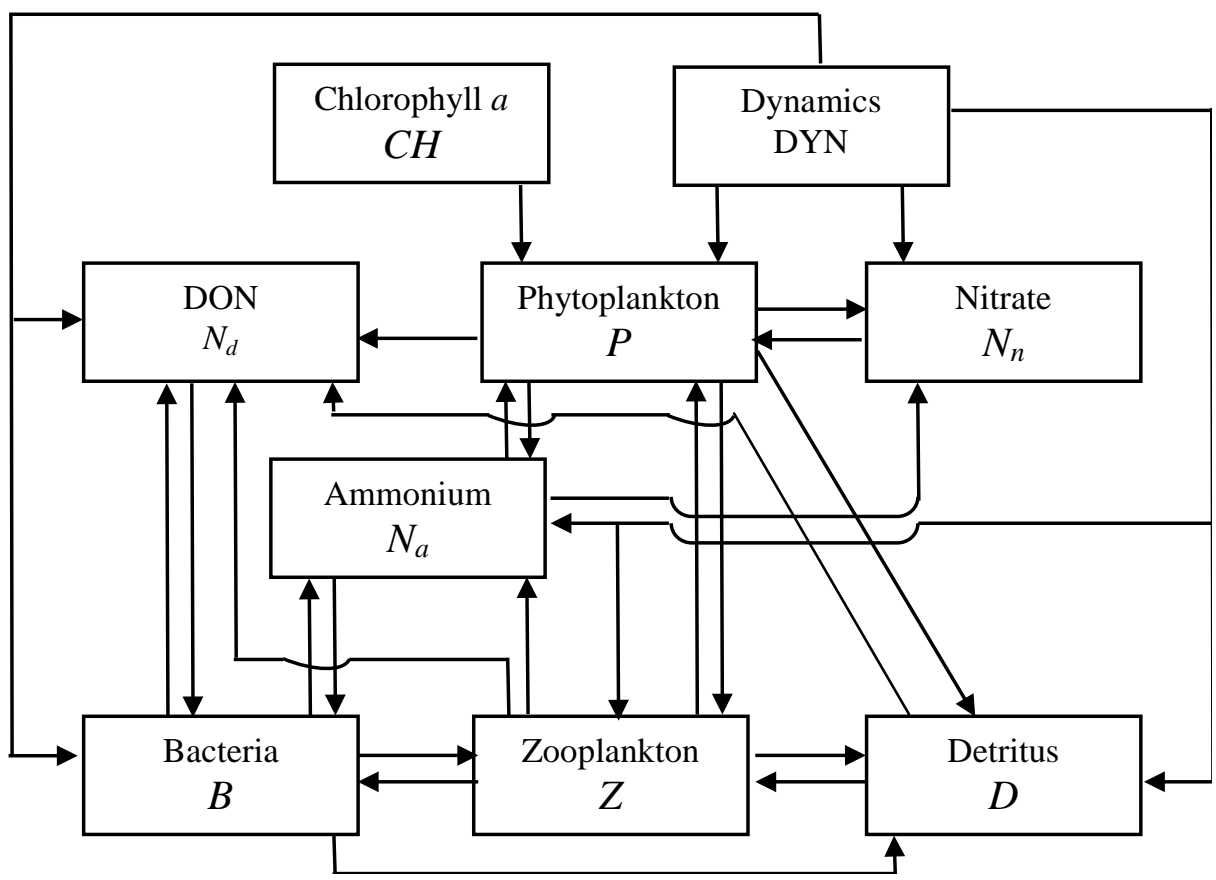

F i g. 1. Conceptual model of the sea upper layer ecosystem based on the Fasham, Ducklow and McKelvie model [11]

Equation of zooplankton concentration:

$\frac{d Z}{d t}=2 r_{Z} Z\left\{C_{Z}-\left[Z-C_{Z}\left(6 C_{B}\right)^{-1} B^{\prime}-C_{Z}\left(6 C_{D}\right)^{-1} D^{\prime}-C_{Z}\left(6 C_{P}\right)^{-1} P^{\prime}-D Y N\left(Z^{\prime}\right)\right]\right\}$.

Equation of bacterial plankton concentration:

$$
\frac{d B}{d t}=2 r_{B} B\left\{C_{B}-\left[B-C_{B}\left(4 C_{N_{d}}\right)^{-1} N_{d}^{\prime}-C_{B}\left(4 C_{N_{a}}\right)^{-1} N_{a}^{\prime}+C_{B}\left(2 C_{Z}\right)^{-1} Z^{\prime}-D Y N\left(B^{\prime}\right)\right]\right\} .
$$

Equation of detritus concentration:

$$
\frac{d D}{d t}=2 r_{D} D\left\{C_{D}-\left[D-C_{D}\left(4 C_{P}\right)^{-1} P^{\prime}-C_{D}\left(4 C_{Z}\right)^{-1} Z^{\prime}+C_{D}\left(4 C_{B}\right)^{-1} B^{\prime}-D Y N\left(D^{\prime}\right)\right]\right\} .
$$

Equation of ammonium concentration:

$$
\begin{aligned}
& \frac{d N_{a}}{d t}=2 r_{N_{a}} N_{a}\left\{C_{N_{a}}-\left[N_{a}+C_{N_{a}}\left(4 C_{P}\right)^{-1} P^{\prime}-C_{N_{a}}\left(2 C_{Z}\right)^{-1} Z^{\prime}+C_{N_{a}}\left(4 C_{B}\right)^{-1} B^{\prime}-\right.\right. \\
& \left.\left.-D Y N\left(N_{a}^{\prime}\right)\right]\right\} .
\end{aligned}
$$

Equation of nitrates concentration:

$$
\frac{d N_{n}}{d t}=2 r_{N_{n}} N_{n}\left\{C_{N_{n}}-\left[N_{n}+C_{N_{n}}\left(2 C_{P}\right)^{-1} P^{\prime}-C_{N_{n}}\left(2 C_{N_{a}}\right)^{-1} N_{a}^{\prime}-D Y N\left(N_{n}^{\prime}\right)\right]\right\} .
$$

Equation of dissolved organic nitrogen concentration:

$$
\begin{aligned}
& \frac{d N_{d}}{d t}=2 r_{N_{d}} N_{d}\left\{C_{N_{d}}-\left[N_{d}-C_{N_{d}}\left(6 C_{P}\right)^{-1} P^{\prime}-C_{N_{d}}\left(6 C_{Z}\right)^{-1} Z^{\prime}+C_{N_{d}}\left(2 C_{B}\right)^{-1} B^{\prime}-\right.\right. \\
& \left.\left.-C_{N_{d}}\left(6 C_{D}\right)^{-1} D^{\prime}-D Y N\left(N_{d}^{\prime}\right)\right]\right\} .
\end{aligned}
$$


The function of $F\left(\mathrm{CH}^{\prime}\right)$ source was applied in the equation for phytoplankton concentration as assimilated observational data, which was the satellite observation of chlorophyll $a$ concentration. The functions of sources $D Y N\left(u_{i}^{\prime}\right)$ took into account the effects of transport and diffusion on the concentrations of the ecosystem biochemical variables, which were reduced to the variation scales of these variables. Each of the equations of system (7) was supplemented by a management agent (6).

Assessment of the effect coefficients in the adaptive model by the normalized ratios of average values of the northwestern Black Sea shelf biochemical fields. To determine the effect coefficients, the information on average values of the northwestern Black Sea shelf biochemical fields (NWS BS) obtained from literature sources was applied in the model (7). The analysis of these sources revealed rather significant spatial-temporal variability of the upper layer ecosystem fields of the mentioned region.

The most productive area for phytoplankton is the Danube part of shelf zone. It is noted that the characteristic features of phytoplankton development here are the absence of nutrient limitation, a sharp increase in terrigenous runoff with flood waters in spring and due to this a limitation of photic zone by 1-2 $\mathrm{m}$ depth [15]. According to the data of [16], the maximum values of phytoplankton concentration at the NWS BS were observed in 1973-1980. (Fig. 2, a), which was due to the strong eutrophication of waters (fragments $a, b, c, d$ of Fig. 2 were taken from [1619] and adapted to the present work). Average phytoplankton concentration in these years in comparison with 1950-1960 increased almost by 17 times, from 0.9 to $16 \mathrm{~g} / \mathrm{m}^{3}$. In 1981-2000 period phytoplankton concentration gradually decreased: in the 1990s it was about $6 \mathrm{~g} / \mathrm{m}^{3}$, and in the 2000s it became $4 \mathrm{~g} / \mathrm{m}^{3}$. These changes are shown in Figure 2, $a$. Based on the presented data, the average value of phytoplankton biomass for the NWS BS region was chosen to be equal to $C_{P}=4 \mathrm{~g} / \mathrm{m}^{3}$.
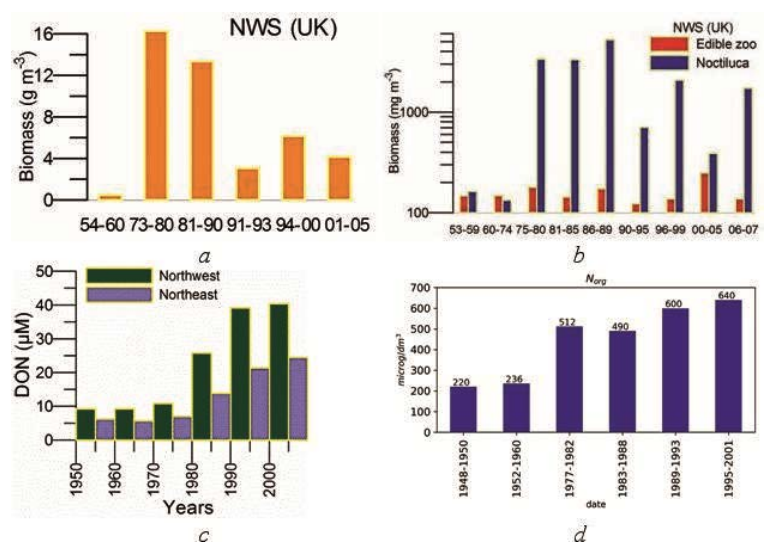

F i g. 2. Data of the multi-year observations on the Black Sea northwestern shelf: $a$ - changes of the phytoplankton biomass in 1954-1960 and 1973-2005 [16]; $b$ - biomass of the fodder zooplancton and Noctiluca scintillans in 1953-2007 [17]; $c$ - variability of the dissolved organic nitrigen on the surface of the western and eastern coastal waters averaged for 5 years [18]; $d-$ average content of nitrogen in organic substance $\left(\mathrm{mcg} / \mathrm{dm}^{3}\right)$ in the surface layer [19] 
Zooplankton spatial distribution is also inhomogeneous. The concentration of plankton organisms is associated with the fresh water distribution in the area of hydrologic fronts, "bloom" zones, the spread of microorganisms and the wind regime. Zooplankton redistribution is significantly affected by the circulation that occurs at offshore and surge winds. According to T. Shiganova [17], in 1990-1995 the fodder zooplankton biomass was $123.4 \mathrm{mg} / \mathrm{m}^{3}$, in 1996-1999 - $138.2 \mathrm{mg} / \mathrm{m}^{3}$; in 2000-2005 it increased to $250.2 \mathrm{mg} / \mathrm{m}^{3}$ and in 2006-2007 it decreased again to $138.4 \mathrm{mg} / \mathrm{m}^{3}$. The diagram in Fig. 2, $b$ characterizes these changes. In this study, for the average value of zooplankton concentration $Z$ the value $C_{Z}=0.4 \mathrm{~g} / \mathrm{m}^{3}$ was taken.

According to [20], $N_{a}$ ammonium nitrogen content in the surface waters widely varied: extremely high concentrations over the entire study period and, accordingly, the range of their variability were observed in the Dnieper-Bug region. $N_{a}$ average concentration on the surface was $18.2 \mu \mathrm{g} / \mathrm{l}$, at $10 \mathrm{~m}$ horizon it decreased to $17.4 \mu \mathrm{g} / \mathrm{l}$ which is $0.158 \mathrm{~g} / \mathrm{m}^{3}$ in terms of recalculation. $N_{a}$ content in the water mixing zone and in the seaward areas of the shelf is significantly lower (about $5.9 \mu \mathrm{g} / \mathrm{l}$ ) [20]. Thus, in the spatial distribution for ammonium nitrogen, as well as for plankton organisms, a tendency for increase in concentration as it approaches the coastal estuaries was observed. We took $N_{a}=0.16 \mathrm{~g} / \mathrm{m}^{3}$ value as the average one.

Spatial and temporal variability range of nitrate concentrations is the largest in the estuary areas of the shelf, especially in the surface layer of the sea. In the Danube region the maximum concentrations (which reached $998 \mu \mathrm{g} / \mathrm{l}$ ) over the entire period of studies were observed. In the water mixing zone nitrate content significantly decreased, the maximum concentrations here did not exceed $250 \mu \mathrm{g} / \mathrm{l}$. In the seawater areas of the NWS BS, distant from the main sources of pollution, the average multiannual nitrate content was $0.1-4.3 \mu \mathrm{g} / \mathrm{l}$. In $20-30 \mathrm{~m}$ layer the average long-term value of the nitrate content in the estuary areas was within 8.3-62.5 $\mu \mathrm{g} /$, in the marine areas - within 0.1-6.7 $\mu \mathrm{g} / \mathrm{l}$. In this work, $C_{N n}=0.11 \mathrm{~g} / \mathrm{m}^{3}$ value was taken as the average multiannual one over the area.

Averaged over 5 [18] years dissolved organic nitrogen concentration in the western and eastern coastal waters is shown in Fig. 2, c. These data were used to assess average multiannual concentration $C_{N d}=4.93 \mathrm{~g} / \mathrm{m}^{3}$.

Estimates of the component average values $\left(\mathrm{g} / \mathrm{m}^{3}\right)$ and the effect coefficients in the ecosystem model

\begin{tabular}{l|l|l|l|l|l|l|l}
\hline$u_{i}$ & \multicolumn{1}{|c}{$P$} & \multicolumn{1}{c}{$Z$} & \multicolumn{1}{c}{$B$} & & \multicolumn{1}{c}{$N_{a}$} & $N_{n}$ & $N_{d}$ \\
\hline$C_{i}$ & 4.0 & 0.4 & 0.46 & 2 & 0.16 & 0.11 & 4.93 \\
\hline \hline$P$ & 1 & 5 & - & - & 6.312 & 9.009 & - \\
$Z$ & 0.017 & 1 & 0.146 & 0.033 & - & - & - \\
$B$ & - & 0.573 & 1 & - & 0.723 & - & 0.023 \\
$D$ & 0.125 & 1.250 & 2.183 & 1 & - & - & - \\
$N_{a}$ & 0.010 & 0.198 & 0.086 & - & 1 & - & - \\
$N_{n}$ & 0.014 & - & - & - & 0.350 & 1 & - \\
$N_{d}$ & 0.205 & 2.053 & 5.379 & 0.411 & - & - & 1 \\
\hline
\end{tabular}

When assessing the average value of bacterial plankton concentration, the observational materials published in $[19,21]$ were used. The data from the mentioned 
works allowed us to take $C_{B}=0.46 \mathrm{~g} / \mathrm{m}^{3}$ value as an average one of bacterial plankton concentration. Based on the materials of [19], we can conclude that the assessment of average multiannual detritus concentration is $C_{D}=2 \mathrm{~g} / \mathrm{m}^{3}$. Thus, in order to assess the values of effect coefficients in the adaptive model of the upper layer ecosystem of NWS BS, we used average multiannual concentrations of biochemical substances which are summarized in the table.

Assimilation of chlorophyll $a$ concentration satellite observations and computational data on the marine environment dynamics in the model. Satellite observations of chlorophyll $a$ concentration and computational data on the marine environment dynamics for the NWS BS region, obtained using Myocean program [22], were used in the model (7) for assimilation. As an example, a map of horizontal currents in the upper layer of this region on the 209th day of 2015, constructed as a result of calculations using the hydrodynamic model, is given in Fig. 3.

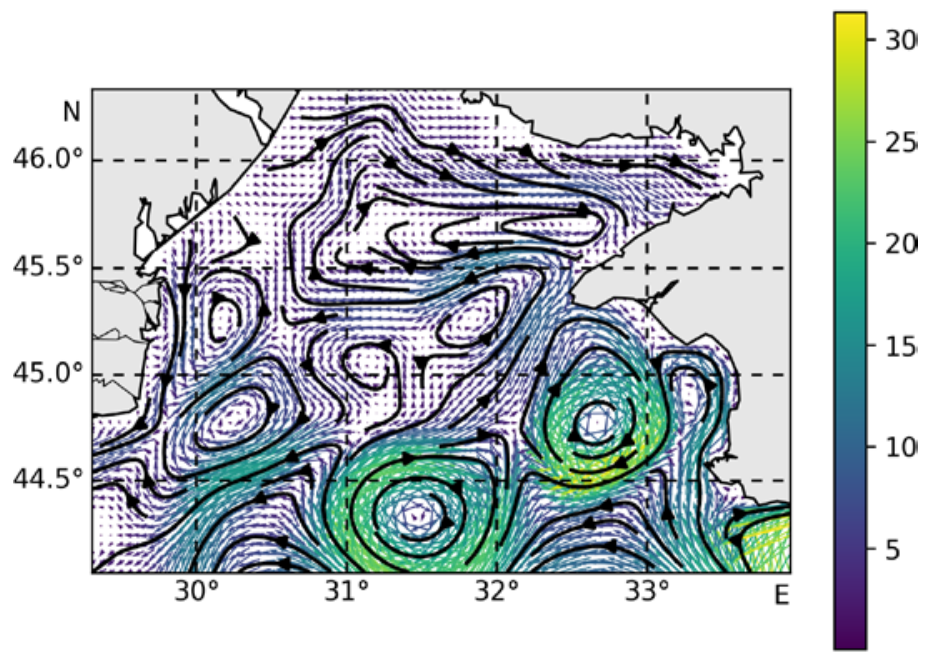

F i g. 3. Map of the horizontal current velocities $(\mathrm{cm} / \mathrm{s})$ in the upper layer of the Black Sea northwestern shelf on the $209^{\text {th }}$ day of 2015 resulted from the calculations by the hydrodynamic model [22]

The equations of ecosystem model (7) are represented in finite differences by the Euler scheme. At the same time, a condition that simplifies their recording is introduced. The relations of computation step in time $\Delta t$ with the specific variation rate of functions $r_{i}$ and average values of model variables $C_{i}$ were taken equal to one: $2 \Delta t_{i} C_{i}=1$. Then modular expressions for the equations of the model (7) in finite differences take the simplified form:

$$
\begin{gathered}
u_{i}^{k+1}=2 u_{i}^{k}\left\{1-\frac{1}{2 C_{i}}\left[u_{i}^{k}-F_{u_{i}}\left[u_{j}^{k}, \operatorname{DYN}\left(u_{i}^{k}\right)\right]\right]\right\}, \\
u_{i}^{k}=\operatorname{IF}\left[u_{i}^{k}<0 ; 0 ; \operatorname{IF}\left(u_{i}^{k}>2 C_{i} ; 2 C_{i} ; u_{i}^{k}\right)\right],
\end{gathered}
$$

where through $F_{u_{i}}\left[u_{j}^{k}, D Y N\left(u_{i}^{k}\right)\right]$ the affecting functions in right parts of equations (7) are denoted. 
The assimilation of observations was preceded by computational experiments, during which the stability of the computational algorithm for solving the equations of the adaptive model and its sensitivity to external effects was tested. The convergence of iterations to the average (stationary) ecosystem state in the absence of external effects turned out to be rather rapid. It was about 5-7 iterations.

Note that stationary values of processes $C_{i}^{*}$ calculated by the model are conditional in the ecosystem with respect to the estimates of the applied effect coefficients. They differ from the estimates $C_{i}$ given in the Table by constant values due to the accepted relation $2 \Delta t r_{i} C_{i}=1$. However, these differences are known, and therefore they can be easily eliminated by introducing constant corrections to the scenarios obtained after assimilating the observational data [14]. The examples of the maps of ecosystem biochemical component fields constructed by assimilating observational data are shown in Fig. 4.
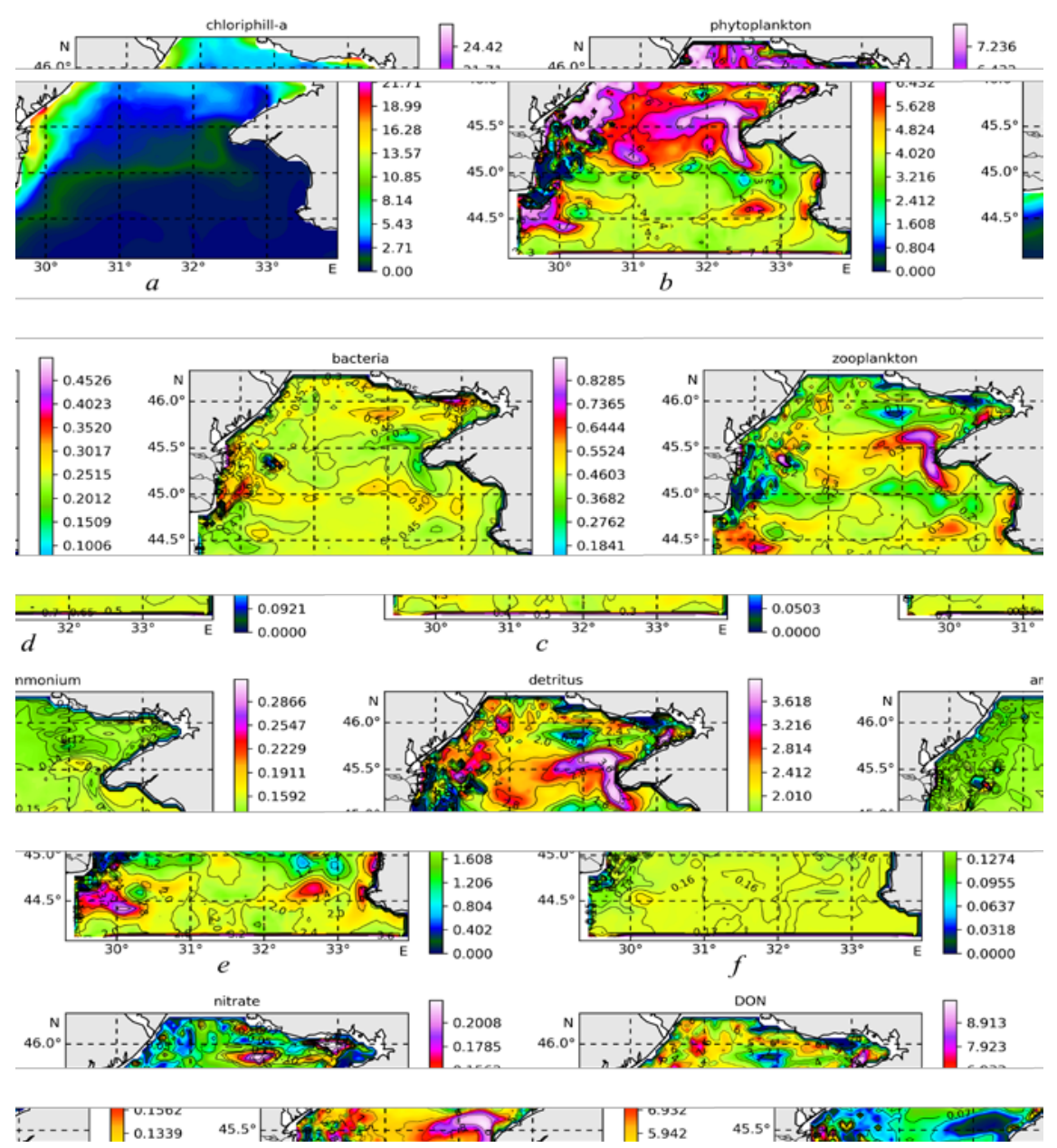

F i g. 4. Maps of the biochemical component fields $\left(\mathrm{g} / \mathrm{m}^{3}\right)$ in the upper layer of the Black Sea northwestern shelf on the $209^{\text {th }}$ day of 2015 resulted from the data assimilation in the ecosystem adaptive model (7), (8) 
For testing the model sensitivity to the assimilated observation data from external information sources, field maps were calculated for every day of 2015. Experiments on separate assimilation of chlorophyll $a$ concentration satellite observations and data characterizing the transport and diffusion of the ecosystem biochemical components were carried out. As the analysis of assimilation results showed, the most detailed maps of spatial-temporal fields of the sea upper layer ecosystem are obtained when the model simultaneously assimilates all available information.

In Fig 4 the maps of fields in the mode of simultaneous assimilation of chlorophyll $a$ concentration satellite observations (Fig. 4, a) and computational data on the marine environment dynamics obtained for this day are shown. Comparing the chlorophyll $a$ concentration spatial distribution, horizontal currents in the upper sea layer and model maps of biochemical fields one can see their specific local similarity in a number of areas. In particular, the specific features of field structure in the area adjacent to the western tip of Crimea due to the dynamics of water are highlighted.

\section{Conclusion}

This work was aimed at showing the possibility of monitoring the dynamics of sea upper layer ecosystem fields using the adaptive dynamic model which has the properties of mutual adaptation of model variables under conditions when new observational data are continuously receiving to the model equations. Assimilation of observations performed the model control function. Adaptation of model estimates of biochemical fields to the observational data was carried out due to the condition of saving the material balances of intrasystem interactions between the modeled processes. This condition underlies the adaptive balance of causes method, which was applied when constructing the ecosystem model. One of the problems was to test the method of presenting intrasystem reactions in the adaptive model using the coefficients, which are the normalized ratios of average values of the fields, which were taken as the ecosystem stationary state.

Computational experiments on the assimilation of satellite observations and computational data on the marine environment dynamics in the adaptive model of the upper layer ecosystem for the northwestern Black Sea shelf region showed that this goal was achieved. Using the observational data assimilation, the maps of the fields of the model biochemical variables, consistent with each other and with external sources of information, were constructed. The possibility of replacing the complex parametrizations, applied in the description of intrasystem interactions in a marine ecosystem, with normalized ratios of average values of the modeled processes in cases where these average values are known from observations was confirmed.

\section{REFERENCES}

1. Sarkisyan, A.S., 2016. Main Directions in the Simulation of Physical Characteristics of the World Ocean and Seas. Izvestiya. Atmospheric and Oceanic Physics, [e-journal] 52(4), pp. 335-340. https://doi.org/10.1134/S0001433816040101

2. $\quad$ Knysh V.V., Nelepo B.A., Sarkisyan A.S., Timchenko I.E., 1978. Dinamiko-Stokhasticheskiy Podkhod k Analizu Nablyudeniy Polya Plotnosti na Gidrofizicheskikh Poligonakh [Dynamic- 
Stochastic Approach to Analysis of Density Field Observations on Hydrophysical Polygons]. Izvestiya AS USSR. Atmospheric and Oceanic Physics, 14(10), pp. 1079-1093 (in Russian).

3. Timchenko, I.E., 1984. Stochastic Modeling of Ocean Dynamics. Chur-London-Paris-NewYork: Harwood Academic Publishers, 320 p.

4. Kochergin, V.P. and Timchenko, I.E., 1987. Monitoring Gidrofizicheskikh Poley Okeana [Monitoring of Oceanic Hydrophysical Fields]. Leningrad: Gidrometeoizdat, 279 p. (in Russian).

5. Ghil, M. and Malanotte-Rizzoli, P., 1991. Data Assimilation in Meteorology and Oceanography. In: R. R. Dmowska and B. Saltzman, eds., 1991. Advances in Geophysics. San Diego: Academic Press. Inc., Vol. 33, pp. 141-266. https://doi.org/10.1016/S0065-2687(08)60442-2

6. Marchuk, G.I. and Zalesny, V.B., 1993. A Numerical Technique for Geophysical Data Assimilation Problems using Pontryagin's Principle and Splitting-up Method. Russian Journal of Numerical Analysis and Mathematical Modelling, [e-journal] 8(4), pp. 311-326. https://doi.org/10.1515/rnam.1993.8.4.311

7. Robinson, A.R. and Lermusiaux, P.F.J., 2000. Overview of Data Assimilation. Harvard Reports in Physical/Interdisciplinary (Ocean Science). Cambridge, Massachusetts: Harvard University. No. 62, 28 p. Available at: http://robinson.seas.harvard.edu/PAPERS/red_report_62.html [Accessed: 06 December 2018].

8. Korotaev, G.K. and Eremeev, V.N., 2006. Vvedenie v Operativnuyu Okeanografiyu Chernogo Morya [Introduction to Operative Oceanography of the Black Sea]. Sevastopol, ECOSIGidrofizika, 382 p. (in Russian).

9. Mizyuk, A.I., Knysh, V.V., Kubryakov, A.I. and Korotaev, G.K., 2009. Assimilation of the Climatic Hydrological Data in the $\sigma$-Coordinate Model of the Black Sea by the Algorithm of Adaptive Statistics. Physical Oceanography, [e-journal] 19(6), pp. 339-357. https://doi.org/10.1007/s11110-010-9058-2

10. Korotaev, G.K., Oguz, T., Dorofeyev, V.L., Demyshev, S.G., Kubryakov, A.I. and Ratner, Yu.B, 2011. Development of Black Sea Nowcasting and Forecasting System. Ocean Science, 7(5), pp. 629-649. https://doi.org/10.5194/os-7-629-2011

11. Fasham, M., Ducklow, H. and McKelvie, S., 1990. A Nitrogen-Based Model of Plankton Dynamics in the Oceanic Mixed Layer. Journal of Marine Research, [e-journal] 48(3), pp. 591-639. https://doi.org/10.1357/002224090784984678

12. Timchenko, I.E., Igumnova, E.M. and Timchenko, I.I., 2000, Sistemnyj Menedzhment i ABCTehnologii Ustojchivogo Razvitija [System Management and ABC-Technologies of Sustainable Development]. Sevastopol: ECOSI-Gidrofizika, 225 p. (in Russian).

13. Timchenko, I.E., Igumnova, E.M. and Timchenko, I.I., 2016. Adaptive Balance Models for Environmental-Economic Systems. CreateSpace Independent Publishing Platform, 486 p.

14. Timchenko, I.E., Lazarchuk, I.P., Igumnova, E.M, 2017. Assimilation of the Observational Data in the Marine Ecosystem Adaptive Model at the Known Mean Values of the Processes in the Marine Environment. Physical Oceanography, [e-journal] (5), pp. 71-86, doi:10.22449/1573-160X-2017-5-71-86

15. Finenko, Z.Z., Churilova, T.Ya. and Suslin, V.V., 2011. Otsenka Biomassy Fitoplanktona i Pervichnoy Produktsii v Chernom More po Sputnikovym Dannym [Assessment of Phytoplankton Biomass and Primary Products in the Black Sea from Satellite Data]. In: V. N. Eremeev, A. V. Gaevskaya, G. E. Shulman, Ju. A. Zagorodnyaya, eds., 2011. Promyslovye Bioresursy Chernogo i Azovskogo Morey [Biological Resources of the Black Sea and Sea of Azov]. Sevastopol: EKOSI-Gidrofizika, pp. 221-236 (in Russian).

16. Nesterova, D., Moncheva, S., Mikaelyan, A., Vershinin, A., Akatov, V., Boicenco, L., Aktan, Y., Sahin, F. and Gvarishvili T., 2008. The State of Phytoplankton. In: BSC, 2008. State of the Environment of the Black Sea 2001-2006/7. Publications of the Commission on the Protection of the Black Sea Against Pollution (BSC) 2008-3. Istanbul. Ch. 5, pp. 173-200. [online] Available at: http://www.blacksea-commission.org/_publ-SOE2009-CH5.asp [Accessed: 06 December 2018]. 
17. Shiganova, T., Musaeva, E., Arashkevich, E., Kamburska, L., Stefanova, K., Mihneva, V., Polishchuk, L., Timofte, F., Ustun, F, Oguz, T., Khalvashi, M. and Tarkan, A.N., 2008. BSC, 2008. State of the Environment of the Black Sea 2001-2006/7. Publications of the Commission on the Protection of the Black Sea Against Pollution (BSC) 2008-3. Istanbul. Ch. 6, pp. 201-246. [online] Available at: http://www.blacksea-commission.org/_publ-SOE2009CH6.asp [Accessed: 06 December 2018].

18. Oguz, T., Velikova, V., Cociasu, A. and Korchenko, A., 2008. The State of Eutrophication. In: BSC, 2008. State of the Environment of the Black Sea 2001-2006/7. Publications of the Commission on the Protection of the Black Sea Against Pollution (BSC) 2008-3. Istanbul. Ch. 2, p. 23-52. [online] Available at: http://www.blacksea-commission.org/_publ-SOE2009CH2.asp [Accessed: 06 December 2018].

19. Zaytsev, Yu.P., Aleksandrov, B.G. and Minicheva, G.G. 2006. Severo-Zapadnaya Chast' Chernogo Morya: Biologiya i Ekologiya [North Western Part of the Black Sea]. Kyiv: Naukova dumka, 701 p. (in Russian).

20. Orlova, I.G., Pavlenko, M.Yu. and Ukraïns'kiy, V.V., 2008. Gidrologichni ta Gidrokhimichni Pokazniki Stanu Pivnichno-Zakhidnogo Shel'fu Chornogo Morya [Hydrological and hydrochemical Indicators of the State of the North-Western Shelf of the Black Sea]. Kiiv: KNT, 616 p. (in Ukranian).

21. Shumakova, G.V., 2002. Mnogoletnyaya Sezonnaya Dinamika Raspredeleniya Bakterioplanktona v Severo-Zapadnoy Chasti Chernogo Morya [Long-Term Seasonal Dynamic of Bakterioplankton in the North-West Black Sea] Ecology of the Sea = Ekologiya moray, (61), pp. 69-73. Available at: https://repository.marine-research.org/handle/299011/4538 [Accessed: 06 December 2018] (in Russian).

22. Copernicus Marine Service Team, 2018. Copernicus. Marine Environment Monitoring Service. [on-line] http://www.myocean.eu/ [Accessed: 06 December 2018].

About the authors:

Igor E. Timchenko - Head of System Analysis Department, FSBSI MHI (2 Kapitanskaya Str., Sevastopol, 299011, Russian Federation), Dr. Sci. (Phys.-Math.), Professor, Researcher ID: A-86502017, timchenko.syst.analysis@mhi-ras.ru

Inga P. Naumenko - Research Associate, System Analysis Department, FSBSI MHI (2 Kapitanskaya Str., Sevastopol, 299011, Russian Federation), Ph.D. (Phys.-Math.), ResearcherID: U-1807-2018, ingaingatm@yandex.ru

Ekaterina M. Igumnova - Leading Engineer, Marine Optics and Biophysics Department, FSBSI MHI (2 Kapitanskaya Str., Sevastopol, 299011, Russian Federation)

Contribution of the co-authors:

Igor E. Timchenko - scientific supervision; statement, formulation, substantiation of the problem; analysis and consolidation of results, preparation of the initial text of the paper

Inga P. Naumenko - literature review, carrying out the numerical calculation, analysis of results, preparation of graphic materials

Ekatrina M. Igumnova - literature review, analysis of the result data, preparation and correction of the paper

All the authors have read and approved the final manuscript.

The authors declare that they have no conflict of interest. 